\title{
Efficacy of intrathecal midazolam on enhancing analgesic effect of fentanyl in patients undergoing lower limb surgery
}

\author{
Masoum Khoshfetrat ${ }^{1}{ }^{*}$, Sima Davarpanah ${ }^{2}$, Aliakbar Keykha $^{3 \odot}$
}

${ }^{1}$ Doctor of Medicine (MD), Fellow of Critical Care Medicine (FCCM), Department of Anesthesiology and Critical Care, Khatam-Al-Anbiya Hospital, Zahedan University of Medical Sciences, Zahedan, Iran

${ }^{2}$ Resident of Anesthesiology and Critical Care, Zahedan University of Medical Sciences, Zahedan, Iran

${ }^{3}$ Master of Science (MSc) in Critical Care Nursing, Community Nursing Research Center, Zahedan University of Medical Sciences, Zahedan, Iran

\section{Correspondence}

Masoum Khoshfetrat, Doctor of Medicine (MD), Fellow of Critical Care Medicine (FCCM), Department of Anesthesiology and Critical Care, Khatam-Al-Anbiya Hospital, Zahedan University of Medical Sciences, Zahedan, Iran

Email: Drkhoshfetrat@yahoo.com History

- Received: 25 August 2018

- Accepted: 30 September 2018

- Published: 17 October 2018

DOI :

https://doi.org/10.15419/bmrat.v5i10.487

\section{Check for updates}

\section{Copyright}

(c) Biomedpress. This is an openaccess article distributed under the terms of the Creative Commons Attribution 4.0 International license.

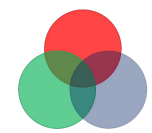

\begin{abstract}
Background: Co-administration of drugs with synergistic effects is considered as one of the methods to increase the effectiveness of intrathecal anesthesia and to reduce the need for injectable analgesics. The purpose of this study was to investigate the efficacy of intrathecal midazolam on enhancing the analgesic effect of fentanyl in patients undergoing lower limb surgery. Materials: The present double-blinded clinical trial was conducted on 90 candidate patients undergoing lower limb orthopedic surgery in 2017 at Khatam-Al-Anbiya Hospital in the city of Zahedan, Iran. To this end, the patients were selected via convenience sampling method and then randomly divided into three groups. Afterwards, 3 cc of $0.5 \%$ hyperbaric Marcaine was injected intrathecally in the first group, 3 cc of Marcaine $+25 \mu \mathrm{g}$ of fentanyl was administered to the second group, and 3 cc of Marcaine $+25 \mu \mathrm{g}$ of fentanyl $+1 \mathrm{mg}$ of midazolam was administered to the third group (the final volume of all three syringes was brought up to $3.7 \mathrm{cc}$ with normal saline). The duration of sensory nerve block and those of motor block and analgesia, as well as changes in vital signs, were then measured in these groups. Moreover, the data were analyzed using SPSS Statistics (Version 22.0) through Chi-square test and one-way analysis of variance (ANOVA). Results:The mean age and gender distribution of the patients in the three study groups did not differ significantly. The mean duration of sensory nerve block was equal to $98.6 \pm 11.1 \mathrm{~min}$ in the first group, $142.2 \pm 12.4$ min in the second group, and $174.3 \pm 10.9$ min in the third group; all showed a statistically significant difference $(P=0.0001, P=0.001, P=0.000)$. The mean duration of analgesia was also reported to be $204.43 \pm 0.3 \mathrm{~min}$ in the first group, $323.62 \pm 7.4 \mathrm{~min}$ in the second group, and $526.22 \pm 0.9 \mathrm{~min}$ in the third group, indicating a statistically significant difference between the three study groups $(P=0.0001, P=0.000, P=000)$. Conclusion: The results of this study demonstrated that adding midazolam to intrathecal fentanyl could significantly increase the duration of sensory nerve block and that of post-operative analgesia.
\end{abstract}

Key words: Fentanyl, Intrathecal Anesthesia, Lower Limb Orthopedic Surgery, Midazolam

\section{INTRODUCTION}

Post-operative pain is considered as one of the common problems in patients. Failure to control pain can thus result in physiological complications, such as hypertension, tachycardia, cardiac dysrhythmia, and even cardiac ischemic events ${ }^{1,2}$. One of the most effective procedures to relieve post-operative pain is systemic opiate injection ${ }^{3}$. Given that injection of systemic intravenous analgesics leads to extensive side effects, including hypotension, respiratory arrest, pruritus and urinary retention ${ }^{4}$, the use of central nervous block is thought to be an appropriate approach to control pain in patients undergoing lower limb surgery ${ }^{1}$. This method is a type of regional anesthesia in which drugs are injected into the subarachnoid space. Therefore, adding low doses of fentanyl to an anesthetic agent may increase the duration of the sensory nerve block and that of the analgesia following surgery. However, it can also cause complications, such as pruritus and respiratory depression ${ }^{5}$. However, a combination of drugs with synergistic effects can enhance the anticipated impacts, and the patient may suffer from fewer side effects due to insignificant concentrations of each drug ${ }^{6}$.

Following the use of intrathecal midazolam for prolongation of spinal anaesthesia, in vitro autoradiography has shown a high density of benzodiazepine (GABAA) receptors in Lamina II of the dorsal horn of the human spinal cord, suggesting a possible role of midazolom in pain modulation ${ }^{7}$. Intrathecal midazolam also causes the release of an endogenous opioid, which acts on the spinal delta receptor ${ }^{8}$. Various studies have found that adding midazolam to bupivacaine increases the duration of post-operative analgesia in a significant manner ${ }^{9}$. However, a study conducted by Kim et al. compared various doses of intrathecal midazolam ( $1 \mathrm{mg}$ and $2 \mathrm{mg}$ plain $0.5 \%$ hyperbaric bupivacaine). They found that the duration

Cite this article : Khoshfetrat M, Davarpanah S, Keykha A. Efficacy of intrathecal midazolam on enhancing analgesic effect of fentanyl in patients undergoing lower limb surgery. Biomed. Res. Ther.; 5(10):2726-2732. 
of the first analgesia was significantly greater in the intrathecal group, compared with the plain bupivacaine group, and was even higher for the $2 \mathrm{mg}$ group ${ }^{10}$.

Overall, the purpose of this study was to investigate the efficacy of using intrathecal midazolam on enhancing the analgesic effect of fentanyl in patients with lower limb surgery.

\section{METHODS}

\section{Study Design, Ethical Considerations, and Patients}

This study was approved by the Vice-Chancellor's Office for Research and Technology and the Ethics Committee at Zahedan University of Medical Sciences (Iran). The study had a code number of IR.ZAUMS.REC.1395.31 and was registered in the Iranian Registry of Clinical Trials (IRCT2017030732923N1). Informed consent was obtained from the patients. This double-blinded clinical trial was conducted on patients admitted for lower limb orthopedic surgery at Khatam-Al-Anbiya Hospital in Zahedan, Iran in 2017.

\section{Sample Size andRandomization}

The sample size was estimated to be 90 patients according to previous studies and given the results of the formula for calculating sample size ${ }^{11,12}$. The patients were also randomly divided into three groups of 30 individuals after their recruitment in the study, based on the inclusion criteria.

\section{Inclusion and Exclusion Criteria}

The inclusion criteria were as follows: patient age between 20-60 years and indications of lower limb orthopedic surgery. Inclusion criteria also consisted of no drug addictions, no history of chronic pain syndrome, no active central nervous system disorders, no psychiatric disorders, no catheter-associated infection, no coagulation disorders (hemophilia, disseminated intravascular coagulation, idiopathic thrombocytopenia, and abnormal coagulation), no spinal abnormalities, and no analgesics within the last 6 hours. Patients were excluded if their surgery lasted for more than three hours with inadequate spinal anesthesia after administration of the medication, and were in need of supplementary or alternative anesthetics.

\section{Interventions}

After inclusion of the patients in the study, the research methodology and assessment of pain intensity by the visual analog scale (VAS) were explained to them the day before the operation by an anesthetist.
The patients were also randomly divided into 3 study groups. At the time of the surgery, an angiocath (20G) was fixed in the left antecubital space for all patients and infusion of Ringer's lactate solution began with 5 $\mathrm{cc} / \mathrm{kg}$. Non-invasive cardiac rhythm monitoring, arterial oxygen saturation, blood pressure, and mean arterial pressure (MAP) were also measured by a monitoring device (Sazgan Gostar, Iran). Then, the patients were placed in their left lateral recumbent position and the spinal needle (25G) was placed in the L3-L4 or L4-L5 interspace in the subarachnoid space using aseptic technique and midline approach. Next, $3 \mathrm{cc}$ of $0.5 \%$ hyperbaric Marcaine was injected intrathecally in the first group (B), $3 \mathrm{cc}$ of Marcaine $+25 \mu \mathrm{g}$ of fentanyl was administered in the second group (BF), and $3 \mathrm{cc}$ of Marcaine $+25 \mu \mathrm{g}$ of fentanyl $+1 \mathrm{mg}$ of midazolam was prescribed for the third group (BFM), with the final volume of all three syringes reaching 3.7 cc by addition of normal saline (Bupivacaine: AstraZeneca, Sweden; Fentanyl: Aburaihan Pharmaceutical Co., and Midazolam: Darou Pakhsh Pharmaceutical Co., Iran). To meet the purpose of blinding, the drugs used in each of the three study groups were prepared by the researcher and presented to an anesthetist, who was unaware of the study, to be injected. After taking the medications, the patients were placed in the supine position. Following anesthetizing at the T10 level, the time was recorded for each patient in pre-designed forms. Surgery was also carried out by the same surgical team. During the surgery, pinprick test was performed for patients every $10 \mathrm{~min}$ utes. If anesthesia was not adequate, general anesthesia would be performed immediately and the patients were excluded from the study.The vital signs of the patients were monitored at minutes of $0,5,10,15$, 20, 25 and 30, and subsequently recorded. After the surgery, the patients were transferred to the recovery ward. When the sensation returned to the T12 level, the time was recorded for each patient, and the patient was transferred to the orthopedic surgical ward. The duration of motor block was also considered from the onset of anesthesia until the first time the patient was able to move the lower limb. The patients" pain intensity was measured by the VAS in the ward by a trained nurse who was unaware of the allocation status of patients in the groups. At each stage, $100 \mathrm{mg}$ of diclofenac suppository would be prescribed if the patient obtained the VAS score over 3. The duration of analgesia was considered from the onset of anesthesia to the first pain relief and analgesic administration. 


\section{Statistical Analysis}

The data were analyzed using the SPSS Statistics software (Version 22.0) via descriptive statistics, Chi-square test, and one-way analysis of variance (ANOVA).

\section{RESULTS}

The mean age of the patients participating in the study was $32.8 \pm 9.9$ years. As well, the gender distribution of the patients included $67(74.4 \%)$ male patients and 23 (25.6\%) female individuals (Figure 1).

The mean age was $33.7 \pm 9.9$ years in the first group (B), $32.9 \pm 10$ years in the second group (BF), and $31.7 \pm 10.2$ years in the third group (BFM). There was also no statistically significant difference between the three study groups. ( $\mathrm{P}=0.717)$. The first group (B) included 24 male patients (80\%) and 6 female individuals (20\%), the second group (BF) consisted of 21 males (70\%) and 9 females (30\%), and the third group was comprised of 22 male individuals (73.3\%) and 8 patients $(26.7 \%)$. No statistically significant difference was observed between the three study groups considering gender distribution $(\mathrm{P}=0.664)$.

From the results of the statistical analysis, using oneway ANOVA, the time to start sensory nerve block was not significant differently between the first (B) and second (BF) groups, between the first (B) and the third (BFM) groups, and between the second (BF) and the third (BFM) groups $(\mathrm{P}=0.698, \mathrm{P}=0.621, \mathrm{P}=0.314)$. Moreover, from the results of the analysis for the time to start motor block, the three groups showed no significant difference $(\mathrm{P}=0.126, \mathrm{P}=0.224, \mathrm{P}=0.635)$. The comparison of duration of sensory nerve block also revealed a significant difference between the three study groups $(\mathrm{P}=0.0001, \mathrm{P}=0.001, \mathrm{P}=0.000)$ (Table 1 ). From comparing the duration of motor block in the three study groups using one-way ANOVA, a significant difference was reported between the three groups $(\mathrm{P}=0.0001, \mathrm{P}=0.000, \mathrm{P}=0.001$ ) (Table 1).Notably,there was a significant difference in the duration of analgesia between the 3 study groups $(\mathrm{P}=0.0001$, $\mathrm{P}=0.000, \mathrm{P}=000$ ).

The changes in the MAP were $77.8 \pm 4.9 \mathrm{~mm} \mathrm{Hg}$ in the first group (B), $78.9 \pm 3.3 \mathrm{~mm} \mathrm{Hg}$ in the second group (BF), and $78.3 \pm 5.9 \mathrm{~mm} \mathrm{Hg}$ in the third group (BFM). No statistically significant differences were observed between the 3 groups ( $\mathrm{P}=0.640$ ) (Figure 2).

The mean heart rate change was $76.9 \pm 7.1 \mathrm{bpm}$ in the first group (B), $75.2 \pm 2.5 \mathrm{bpm}$ in the second group (BF), and $75.3 \pm 5.1 \mathrm{bpm}$ in the third group (BFM). There was no statistically significant difference between or among the three study groups $(\mathrm{P}=0.360)$ (Figure 3).

\section{DISCUSSION}

The results of this study showed that adding midazolam to intrathecal anesthesia could increase the duration of sensory nerve block and those of motor block and analgesia without any complications. In line with these results, Gupta et al. investigated the addition of midazolam to fentanyl in the intrathecal anesthesia in patients with lower limb surgery; they reported that adding midazolam to intrathecal anesthesia could improve the duration of the motor block and that of analgesia without any hemodynamic complications.In concordance with the results of this study, it should be noted that the start times of the sensory nerve block and motor block was measured for patients, and a very slight difference was observed; however, no significant difference was reported between the groups ${ }^{1}$. The basis of using intrathecal midazolam is that the GABAA receptor agonist is located in the binding site of benzodiazepines, and the agonist saturation of the binding site of benzodiazepines increases GABA activity in the GABAA receptor. This receptor is a chloride ionophore that maintains the potential of the membrane at or near the resting potential when activated and consequently reduces neuronal excitability. Some drugs also have systemic absorption, increasing the duration of sensory nerve block, motor block and analgesia afterwards ${ }^{13}$. In this regard, Cox et al. suggested that administering intrathecal midazolam could target different intrathecal receptors, which could increase the duration of analgesia and lead to its better quality.

The mentioned study was conducted in vitro and in vivo animal conditions and it was mostly used to examine the effect of the drug on the opioid receptors in the body ${ }^{14}$.Contrary to the results of this study, Kim et al. reported that the use of midazolam in the intrathecal anesthesia could reduce the onset of the sensory nerve block, but changes in other variables of the duration of sensory nerve block, motor block, and analgesia were similar to those in the current study. The main difference between the results of the two investigations was that the mentioned study did not use fentanyl and compared only two different doses (1 and $2 \mathrm{mg}$ ) of midazolam with the control group.They stated that the number of complications and the time of the blocks in the two doses did not differ statistically but they were different from the control group ${ }^{10}$. Contrary to the results, Francis et al. indicated that the addition of midazolam to fentanyl had no effect on intrathecal anesthesia and could not improve patients' durability of the sensory nerve block as well as the duration of the motor block and analgesia. 


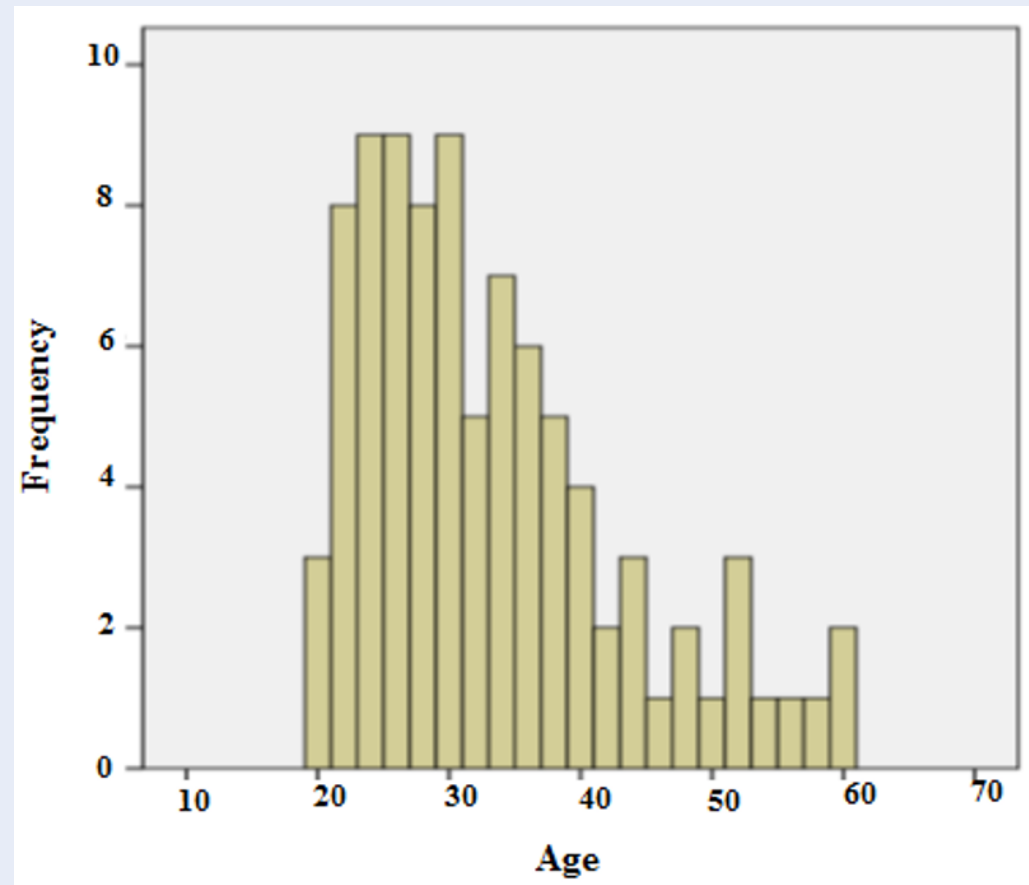

Figure 1: Frequency distribution of research subjects. Most of the patients were between the ages of 20 and 30 years. This age distribution was close to each other and did not show any significant difference.

Table 1: Comparison of time/duration of spinal block variables (minute)

\begin{tabular}{lccc}
\hline \multicolumn{1}{c}{ Variables } & First group (B) & Second group (BF) & Third group (BFM) \\
$\begin{array}{l}\text { Time to start sensory nerve } \\
\text { block (minute) }\end{array}$ & $13.08 \pm 3.1$ & $11.31 \pm 2.04$ & $11 \pm 1.18$ \\
$\begin{array}{l}\text { Time to start motor block } \\
\text { (minute) }\end{array}$ & $15 \pm 2.8$ & $13.1 \pm 1.06$ & $12 \pm 0.8$ \\
$\begin{array}{l}\text { Duration of sensory nerve } \\
\text { block (minute) }\end{array}$ & $98.11 \pm 6.1$ & $142.12 \pm 2.4$ & $174.10 \pm 3.9$ \\
$\begin{array}{l}\text { Duration of motor block } \\
\text { (minute) }\end{array}$ & $86 \pm 140.3$ & $125.7 \pm 9.4$ & $157.3 \pm 9.9$ \\
$\begin{array}{l}\text { Duration of analgesia } \\
\text { (minute) }\end{array}$ & $204.43 \pm 0.3$ & $323.63 \pm 7.4$ & $526.82 \pm 0.9$ \\
\hline
\end{tabular}

The dosage of drugs used in their study slightly varied with that injected in the present study. They used 20 $\mu \mathrm{g}$ of fentanyl and $2 \mathrm{mg}$ of midazolam, which could not account for the difference in the results of the two studies ${ }^{3}$.Routray et al. also reported that adding clonidine to fentanyl in the intrathecal anesthesia could increase the duration of post-operative analgesia. Although the type of medications used in these two studies was completely different, it was concluded that the addition of another drug to fentanyl could enhance its effects and even be useful in controlling post-operative pain ${ }^{15}$.Singh et al. also compared the addition of two different doses of fentanyl, and clonidine to bupivacaine, in intrathecal anesthesia and reported that both doses could reduce the duration of anesthesia better than that of the control group, and increases the duration of sensory nerve block, motor block, and analgesia following surgery ${ }^{16}$.

Moreover, Tucker et al. used a combination of $2 \mathrm{mg}$ of midazolam and $10 \mu \mathrm{g}$ of fentanyl to control labor pain and reported that the given method could more effectively control pain. Although patients and doses were different, the results were the same ${ }^{17}$. Abdollahpour et al. also argued that addition of midazolam 


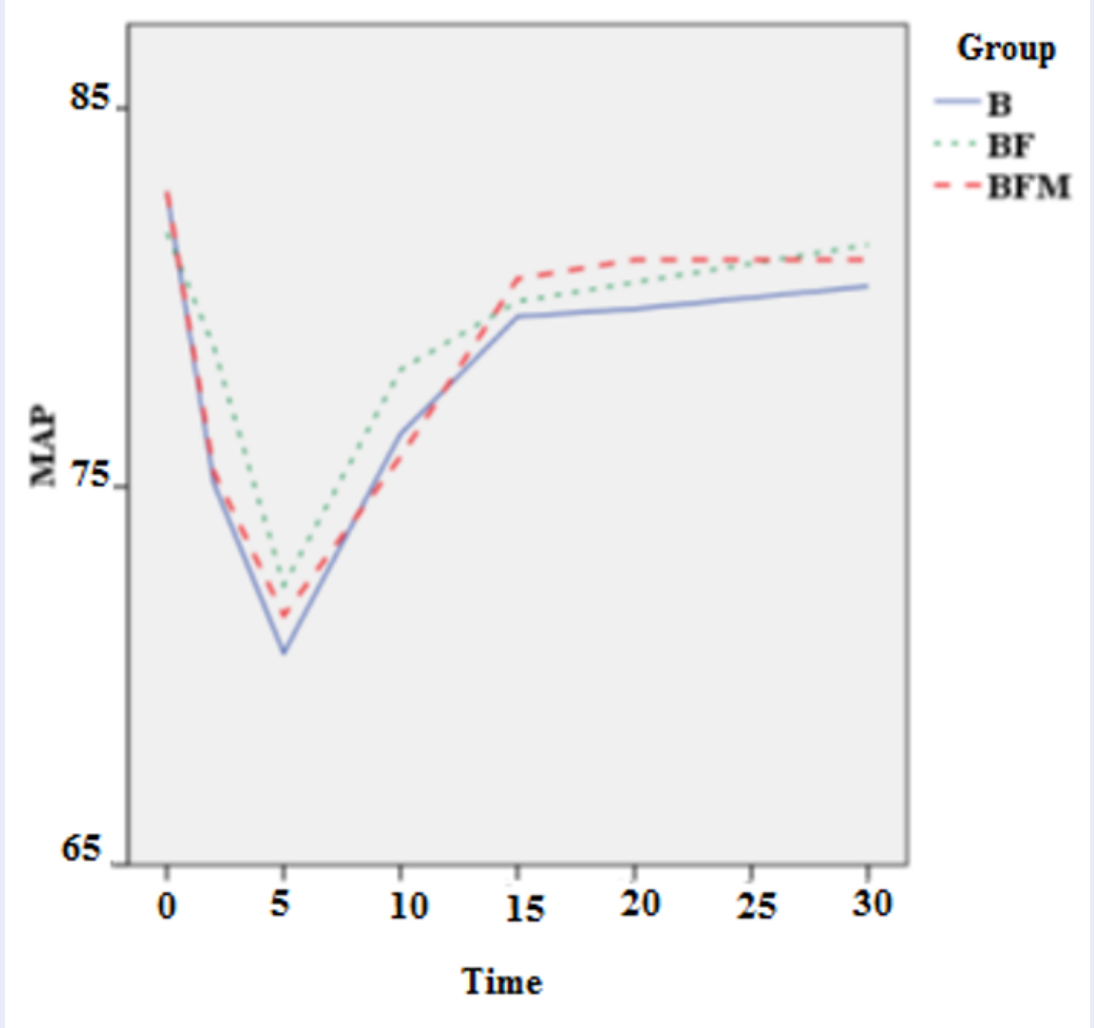

Figure 2: Comparison of MAP changes in the three study groups. Immediately after spinal anesthesia, the mean arterial pressure dropped significantly in all three groups. And then, in all three groups, there was a rising trend. In the BFM group, the mean arterial pressure was better than the other two groups, but there was no significant difference between the three groups.

and sufentanil in the intrathecal anesthesia in elective Cesarean-section could reduce the onset of anesthesia and increase the duration of analgesia, but it did not change during motor recovery. The use of sufentanil similarly increased the time of the first request for analgesic administration, but none of the drugs had an impact on the incidence of Apgar score of newborns. Moreover, increased chills were observed in women. Although midazolam reduced hypotension and nausea, the results of the above study were in line with the findings of our present study.

Since the use of midazolam in different patients has little side effects, it could be used with confidence in the intrathecal anesthesia ${ }^{18}$. Safari et al. also investigated the effect of using fentanyl and midazolam on intrathecal anesthesia in drug-dependent patients versus controls receiving bupivacaine alone; they reported that the duration of sensory nerve block was longer in both fentanyl and midazolam groups than that in the control group, although this was longer in the midazolam group.
Unlike the present study, there was a consensus on the increase in the duration of sensory nerve block, even if fentanyl and midazolam were not used in the mentioned study. Given the fact that the patients were drug-dependent, the likelihood of drug use syndrome could justify different results ${ }^{11}$. In the study by Francis et al., the duration of sensory nerve block and analgesia were longer in the group receiving midazolam than that in the fentanyl group. This study used $2 \mathrm{mg}$ of midazolam, which was twice as high as the dose administered in this study. The dose of fentanyl used was $20 \mu \mathrm{g}$, which was less than what is employed in the present study ${ }^{3}$. Furthermore, there was no significant difference in heart rate and MAP between the groups. The vital signs showed no significant changes in previous studies by adding fentanyl, midazolam, or clonidine to bupivacaine to our journey ${ }^{1,15,19}$. One of the limitations of this study was the type of orthopedic injury severity in patients was not the same and this could be effective at the onset of the patient's pain and distort the results. 


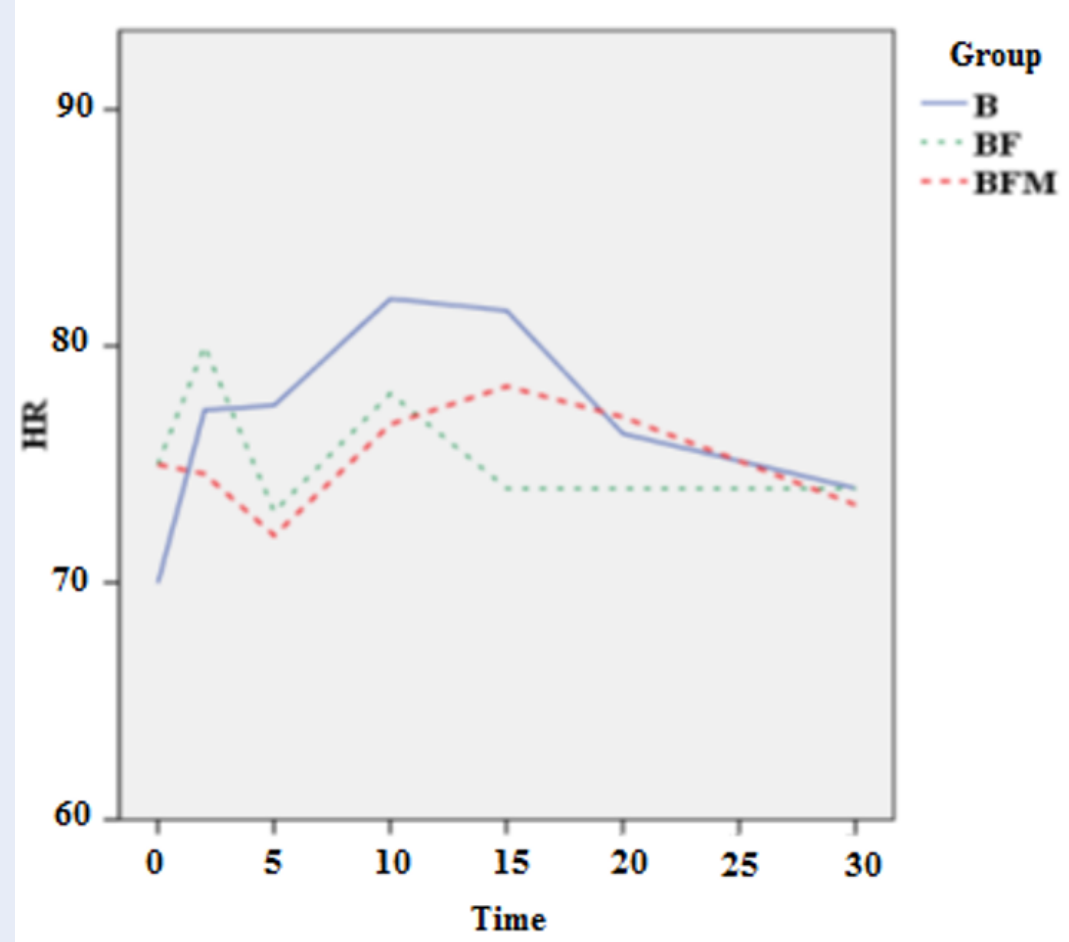

Figure 3: Comparison of heart rate changes in the three study groups. The first time after spinal anesthesia, in the first and second group, the heart rate increased and in the first group, this increase continued until the 15th minute after the study but after that, the heart rate of the patients was close to the three groups.

\section{CONCLUSION}

The present study demonstrated that a combination of midazolam to fentanyl could significantly reduce duration of sensory nerve block and those of motor block and analgesia after surgery, but no complications for the patients were observed.

\section{COMPETING INTERESTS}

The authors expressed no financial conflict of interest.

\section{AUTHORS' CONTRIBUTIONS}

Masoum Khoshfetrat: participation in implementation of the research, supervision of data collection, and revision of the article. Sima Davarpanah: participation in implementation of the research and data collection. Aliakbar Keykha: compilation of the article and its precise editing. All authors reviewed, commented, and approved the final version of the article.

\section{FUNDING}

The present study was financially supported by Zahedan University of Medical Sciences, Zahedan, Iran.

\section{ACKNOWLEDGMENTS}

This study was derived from a Master's Thesis written by a Resident of Anesthesiology and Critical Care, approved and funded by the Vice-Chancellor's Office for Research and Technology at Zahedan University of Medical Sciences. The researchers, hereby, would like to express their gratitude to the Vice-Chancellor's Office for Research and Technology as well as the staff of the orthopedic surgery ward at Khatam-Al-Anbiya Hospital in the city of Zahedan, Iran.

\section{REFERENCES}

1. Gupta A, Kamat H, Kharod U. Efficacy of intrathecal midazolam in potentiating the analgesic effect of intrathecal fentanyl in patients undergoing lower limb surgery. Anesthesia, Essays and Researches. 2015;9:379-83. Available from: Doi:10.4103/ 0259-1162.164650.

2. Breivik H. Postoperative pain management: why is it difficult to show that it improves outcome? European Journal of Anaesthesiology. 1998;15:748-51. Available from: Doi: 10.1097/00003643-199811000-00022.

3. Codero $F$, Vitalis $M$, Thikra S. A randomised controlled trial comparing the effect of adjuvant intrathecal $2 \mathrm{mg}$ midazolam to 20 micrograms fentanyl on postoperative pain for patients undergoing lower limb orthopaedic surgery under spinal anaesthesia. African Health Sciences. 2016;16:282-91. Available from: DOI:10.4314/ahs.v16i1.37.

4. Dureja GP, Usmani H, Khan M, Tahseen M, Jamal A. Efficacy of intrathecal midazolam with or without epidural methylprednisolone for management of post-herpetic neuralgia involv- 
ing lumbosacral dermatomes. Pain Physician. 2010;13:21321.

5. Idowu OA, Sanusi AA, Eyelade OR. Effects of intrathecally administered fentanyl on duration of analgesia in patients undergoing spinal anaesthesia for elective caesarean section. African Journal of Medicine and Medical Sciences. 2011;40:213-9.

6. Ho KM, Ismail $\mathrm{H}$. Use of intrathecal midazolam to improve perioperative analgesia: a meta-analysis. Anaesthesia and Intensive Care. 2008;36:365-73.

7. Faull RL, Villiger JW. Benzodiazepine receptors in the human spinal cord: a detailed anatomical and pharmacological study. Neuroscience. 1986;17:791-802. Available from: Doi:10.1016/ 0306-4522(86)90045-X.

8. Goodchild CS, Guo Z, Musgreave A, Gent JP. Antinociception by intrathecal midazolam involves endogenous neurotransmitters acting at spinal cord delta opioid receptors. British Journal of Anaesthesia. 1996;77:758-63. Available from: DOI: 10.1093/bja/77.6.758.

9. Imani F, Mirdehghan M, Entezary S, Kashi AM. Evaluation of Maternal and Neonatal Effects of Adding Midazolam to Bupivacaine under Combined Spinal-Epidural Anesthesia in Elective Cesarean Section. Majallah-i Ulum-i Pizishki-i Razi. 2009;15:27-36.

10. Kim MH, Lee YM. Intrathecal midazolam increases the analgesic effects of spinal blockade with bupivacaine in patients undergoing haemorrhoidectomy. British Journal of Anaesthesia. 2001;86:77-9. Available from: DOI:10.1093/bja/86.1.77.

11. Safari F, Dabbagh A, Sharifnia M. The effect of adjuvant midazolam compared with fentanyl on the duration of spinal anesthesia with $0.5 \%$ bupivacaine in opium abusers. Korean Journal of Anesthesiology. 2012;63:521-6. Available from: DOI:10.4097/kjae.2012.63.6.521.

12. Gupta A, Kamat $H$, Kharod U. Efficacy of intrathecal midazolam in potentiating the analgesic effect of intrathecal fentanyl in patients undergoing lower limb surgery. Anesthesia, Essays and Researches. 2015;9:379-83. Available from: Doi:10.4103/ 0259-1162.164650.

13. Chattopadhyay A, Maitra S, Sen S, Bhattacharjee S, Layek A, Pal S. A study to compare the analgesic efficacy of intrathecal bupivacaine alone with intrathecal bupivacaine midazolam combination in patients undergoing elective infraumbilical surgery. Anesthesiology Research and Practice. 2013;2013:567134. Available from: Doi:10.1155/2013/567134

14. Cox RF, Collins MA. The effects of benzodiazepines on human opioid receptor binding and function. Anesthesia and Analgesia. 2001;93:354-8.

15. Routray SS, Raut K, Pradhan A, Dash A, Soren M. Comparison of intrathecal clonidine and fentanyl as adjuvant to hyperbaric bupivacaine in subarachnoid block for lower limb orthopedic surgery. Anesthesia, Essays and Researches. 2017;11:589-93. Available from: DOI:10.4103/aer.AER_91_17.

16. Singh R, Kundra S, Gupta S, Grewal A, Tewari A. Effect of clonidine and/or fentanyl in combination with intrathecal bupivacaine for lower limb surgery. Journal of Anaesthesiology, Clinical Pharmacology. 2015;31:485-90. Available from: Doi: 10.4103/0970-9185.169069.

17. Tucker AP, Mezzatesta J, Nadeson R, Goodchild CS. Intrathecal midazolam II: combination with intrathecal fentanyl for labor pain. Anesthesia and Analgesia. 2004;98:1521-7. Available from: Doi:10.1213/01 ane 0000112434.68702.e4.

18. Abdollahpour A, Azadi R, Bandari R, Mirmohammadkhani M Effects of adding midazolam and sufentanil to intrathecal bupivacaine on analgesia quality and postoperative complications in elective cesarean section. Anesthesia and Pain Medicine. 2015;5:e23565. Available from: DOI:10.5812/aapm. 23565.

19. Kararmaz A, Kaya S, Turhanoglu S, Ozyilmaz MA. Low-dose bupivacaine-fentanyl spinal anaesthesia for transurethral prostatectomy. Anaesthesia. 2003;58:526-30. Available from: DOI:10.1046/j.1365-2044.2003.03153.x. 